\title{
UNMANNED AERIAL VEHICLE - A TOOL FOR ACQUIRING SPATIAL DATA FOR RESEARCH AND COMMERCIAL PURPOSES. NEW COURSE IN THE GEOGRAPHY AND CARTOGRAPHY CURRICULUM IN HIGHER EDUCATION
}

\author{
J. Jeziorska ${ }^{a}$ \\ ${ }^{a}$ University of Wroclaw, Institute of Geography and Regional Development, \\ Department of Geoinformatics and Cartography, Wrocław, Poland \\ (justyna.jeziorska@uni.wroc.pl)
}

\section{Commission VI}

KEY WORDS: Unmanned Aerial Vehicle, curriculum, Geography and Cartography, Higher Education

\begin{abstract}
:
This paper describes the syllabus for the innovative course „Unmanned aerial observations of Terrain” introduced to the curriculum by the Department of Geoinformatics and Cartography of the University of Wroclaw (Poland). It indicates the objectives of the new subject, its didactic purpose, methods used in the teaching process, specifications of teaching materials, and the knowledge and skills that students are expected to acquire. Finally, it presents the content of the course and description of lesson units.

The subject will be obligatory for graduate students majoring in Geography, who are participants in the Geoinformatics and Cartography Master's program. Thirty-eight hours in a summer semester has been earmarked for the course. That includes 30 hours of instructor-guided laboratory and fieldtrip work, and 8 hours of individual work.

The course aims to prepare future geographers to conduct a multi-step process that includes defining the purpose of using UAV in light of the chosen research problem, preparation of the mission, flight execution; geoprocessing of acquired aerial imagery; generation of cartomertic final products, and analysis of outcomes in order to answer the initially asked research question. This comprehensive approach will allow students, future experts in the field of geoinformatics and cartography, to gain the skills needed to acquire spatial data using an UAV, process them, and apply the results of their analysis in practice.
\end{abstract}

\section{INTRODUCTION}

Spatial information plays a crucial role in modern society. The Unmanned Aerial Vehicle (UAV), which is defined as a vehicle flying in the air with no person on board with the capability of controlling the aircraft (Eisenbeiss, 2009) is a tool for spatial data acquisition with great potential for science and economics. Hence the ability to operate a UAV is a desirable skill in the job market and in the world of science. There is no doubt that students should learn how to use them efficiently. Many educational facilities conduct research using UAVs, but yet only few of them include courses in the curriculum that enable students to learn how to operate the UAV. So far the opportunity to study design, construction, and UAV operation has been limited to engineering schools, and the need for educating future geographers, cartographers and spatial planners in how to use UAV technology for research and commercial purposes seems to be neglected.

\section{TEACHING PROGRAM}

\subsection{Concept and outline}

The Department of Geoinformatics and Cartography of the University of Wroclaw (Poland) decided to introduce to the curriculum an innovative subject - Unmanned Aerial Observations of Terrain.

The opportunity to modify the program of studies came about because of recent changes in the Polish higher education system due to implementing the National Qualifications Framework.
This Master's course is intended for first-year Geoinformatics and Cartography majors. Thirty-eight hours in a summer semester has been earmarked for the course. That includes 30 hours of instructor-guided laboratory and fieldtrip work, and 8 hours of individual work.

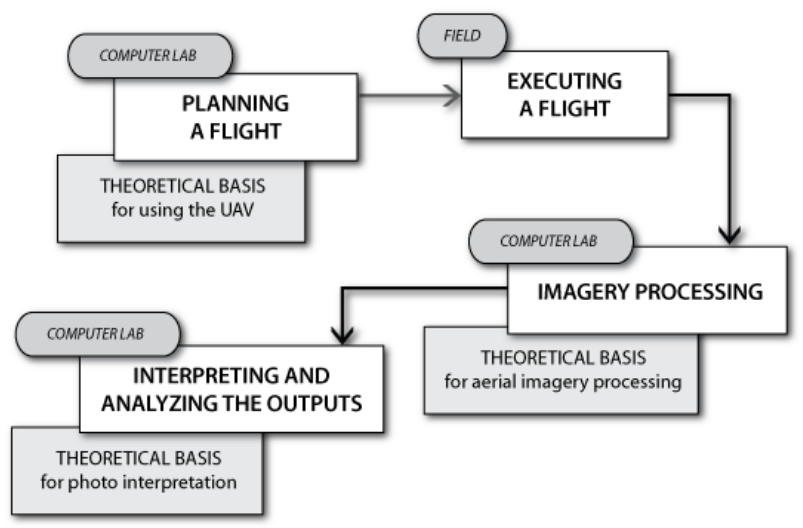

Figure 1. Schematic overview of teaching program - stages of learning how to use the UAV as a research tool

The comprehensive approach to the subject requires a multi-step process of knowledge acquisition. The lesson units (45-minutes long) have been grouped into blocks based on the topic and time requirements.

The underlying idea of the course is the multi-stage conception of learning. Each student should know the outcome and purpose of learning the usage of UAV from the beginning of the course. 
The holistic process includes several phases, depicted in Figure 1. Based on theoretical knowledge about Unmanned Aerial Systems, students create a flight plan and execute a preprogrammed flight during the field trip. Afterwards, they process the acquired imagery in the dedicated software, and finally analyze the outputs. In the first stage of learning, the students try to find a research problem that can be solved based on the data provided by UAV. The following stages lead directly to finding the solution to this problem. This approach assures each student that every task conducted during the lesson has its purpose and brings closer the outcome of finding the answer to the scientific question.

\subsection{Teaching materials}

The course requires a variety of teaching materials. Although the developed curriculum doesn't require a specific model of UAV or software, the teaching process described in this publication is based on the features and materials available at the University of Wroclaw (Tab.1).

Table 1. Features and materials used in the teaching process for the course at University of Wroclaw

\begin{tabular}{|l|l|}
\hline $\begin{array}{l}\text { Features and } \\
\text { materials }\end{array}$ & $\begin{array}{l}\text { Parameters of the features and } \\
\text { materials used in the course }\end{array}$ \\
\hline Computer laboratory & $\begin{array}{l}\text { The computer laboratory of } \\
\text { Geographic Information Systems, } \\
13 \text { computer units }\end{array}$ \\
\hline $\begin{array}{l}\text { Unmanned Aerial } \\
\text { Vehicle }\end{array}$ & $\begin{array}{l}\text { swinglet CAM, produced by } \\
\text { senseFly }\end{array}$ \\
\hline \multicolumn{1}{|c|}{ on-board camera } & Canon Ixus-120IS \\
\hline $\begin{array}{l}\text { Software for flight plan } \\
\text { preparation }\end{array}$ & $\begin{array}{l}\text { e-mo-tion, produced by senseFly } \\
\text { MapTiler }\end{array}$ \\
\hline $\begin{array}{l}\text { Study area appropriate } \\
\text { for flight execution }\end{array}$ & $\begin{array}{l}\text { Depends on the chosen research } \\
\text { project }\end{array}$ \\
\hline $\begin{array}{l}\text { Software for imagery } \\
\text { processing }\end{array}$ & $\begin{array}{l}\text { PostFlight Suite } \\
\text { Agisoft Photoscan Professional }\end{array}$ \\
\hline
\end{tabular}

The Institute of Geography and Regional Development at the University of Wroclaw owns an Unmanned Aerial Vehicle swinglet CAM manufacured by the Swiss company named senseFly. The comprehensive system swinglet CAM illustrated in Fig. 2 consists of a $0,5 \mathrm{~kg}$ flying wing (Fig. 2a), including a full-featured autopilot and an integrated $12 \mathrm{MP}$ still camera (Fig. 2e), as well as the ground control station (Fig. 2b), which is equipped with a notebook computer with dedicated software installed and a remote control. (Fig. 2c).

Apart from the Unmanned Aerial Vehicle itself, the host institution needs to provide each student with computer unit. In order to process the acquired aerial imagery, each computer unit should have the necessary software installed. The application needed for the geoprocessing of acquired imagery can be chosen from a variety of software options available on the market. Agisoft Photoscan Professional, used in this case study, was chosen because of particular features it offers. Most notably, it offers the possibility of using a free demo version that maintains full functionality, but doesn't allow export or saving the output products. In this way, the students are able to learn the whole process, while the results are generated and saved by one computer unit with the full version of software. Another advantage of the software lies in the available option of purchasing the educational license. Additionally, the opensource software MapTiler is used to generate tiles incorporated as customized base maps into e-mo-tion.

The manufacturer of swinglet CAM also provides the PostFlight Suite that is used for geotagging of aerial imagery.
An obvious requirement for the flight is an appropriate study area that fulfills all of the topographical and legal requirements for flight execution.

The lack of textbooks concerning the topic of UAV emphasizes the need for students to refer to a variety of reading resources. They are also provided with a dedicated tutorial created for the course, which contains the description of the topics addressed in each block unit and the reading resources concerning these topics. It is also advisable to use the guidebooks and instructions provided by the UAV manufacturer and software developers.

\subsection{Teaching methods}

The teaching methods used represent a modern approach to the education process: learning through practice. The role of the teacher in the whole process is as a guide or tutor rather than as a knowledge provider. This approach will prepare students for independent critical thinking, presenting their own ideas in front of the group and defending their point of view, and finally taking responsibility for their own decisions. Thus the course objectives include not only gaining knowledge, but also developing social skills

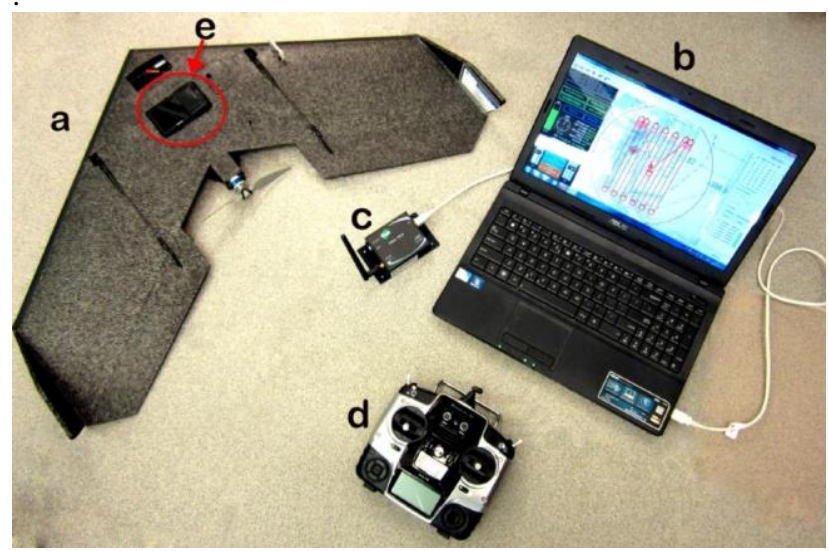

Figure 2. Elements of swinglet CAM system:

(a) UAV, (b) ground control station, (c) radiomodem,

(d) remote control, (e) camera 12MP

The emphasis is put on students' own creativity, asking questions and seeking answers, and practicing skills rather than memorizing definitions. The program represents a continuous procedure. The first step is to determine a problem that can be solved using data obtained by UAV (group work). Then students search for the appropriate research area. They present their idea in public and compete with other groups, because only one project will be chosen to be realized in the next phase. The creation of a flight plan is performed in the computer laboratory and a field trip is organized for the execution of the flight. The last two phases, geoprocessing and analysis, also require the use of computers.

\section{COURSE CONTENT}

Innovative teaching methods require changing the commonly used practice in the Polish high education system: two-unit blocks per week for the course. Grouping more lesson units into thematic blocks allows a comprehensive approach to be maintained, where each block unit corresponds to a complete step in the learning process (see Fig.1). The only topic that requires two block units is the time consuming "Flight preparation." Table 2 presents the tasks and objectives for each block unit, and the outline of each one is described. 
Table 2. Tasks and learning objectives of the course

\begin{tabular}{|c|c|c|}
\hline \multicolumn{2}{|c|}{ unit } & Tasks and learning objectives \\
\hline \multirow[b]{2}{*}{ 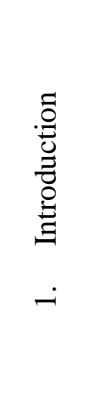 } & 1 & $\begin{array}{l}\text { - Outline and summary of topics to be covered } \\
\text { in the course } \\
\text { - Safety rules and grading system. }\end{array}$ \\
\hline & 3 & $\begin{array}{l}\text { The principles of Unmanned Aerial Systems. } \\
\text { - Why do we need UAV? - methods of } \\
\text { obtaining spatial data. } \\
\text { - Unmanned aerial vehicles - classification and } \\
\text { global review. } \\
\text { - The UAV swinglet CAM - getting to know } \\
\text { the comprehensive system. }\end{array}$ \\
\hline \multirow{5}{*}{ 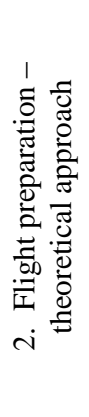 } & 4 & \multirow{5}{*}{$\begin{array}{l}\text { What is the photogrammetric flight? } \\
\text { - The steps of planning the flight. } \\
\text { - Legal restrictions and formal procedures for } \\
\text { obtaining a flight permission. } \\
\text { - Choosing an optimal starting point. } \\
\text { Getting to know the software e-motion. } \\
\text { - How to program and monitor the swinglet. } \\
\text { - Customizing the base maps for the e-motion } \\
\text { software - producing the base tiles in the } \\
\text { MapTiler. } \\
\text { Introduction to the PROJECT TASK. }\end{array}$} \\
\hline & 5 & \\
\hline & 6 & \\
\hline & 7 & \\
\hline & 8 & \\
\hline \multirow{5}{*}{ 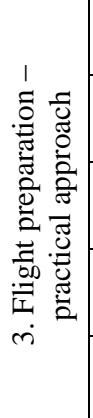 } & 9 & \multirow{5}{*}{$\begin{array}{l}\text { Presentation of the PROJECT TASK. } \\
\text { - Brainstorming the ideas - choosing the best } \\
\text { project. } \\
\text { Pre-planning the flight for the chosen project. } \\
\text { - Preparing the flight using the e-mo-tion } \\
\text { software and saving into the memory of the } \\
\text { autopilot. } \\
\text { - Obtaining the flight permission for a chosen } \\
\text { location - filling in the required documents. } \\
\text { - Preparing the swinglet for a flight -charging } \\
\text { procedures and safety checks. }\end{array}$} \\
\hline & 10 & \\
\hline & 11 & \\
\hline & 12 & \\
\hline & 13 & \\
\hline \multirow{8}{*}{ 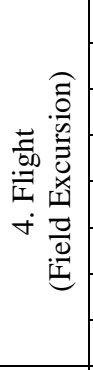 } & 14 & \multirow{8}{*}{$\begin{array}{l}\text { Executing the preprogrammed photo flight. } \\
\text { - Weather check. } \\
\text { - Terrain check. } \\
\text { - Preparing the swinglet. } \\
\text { - Pre-flight check. } \\
\text { - Start-up. } \\
\text { - Establishing communication. } \\
\text { - Take-off and flight. } \\
\text { - Landing. }\end{array}$} \\
\hline & 15 & \\
\hline & 16 & \\
\hline & 17 & \\
\hline & 18 & \\
\hline & 19 & \\
\hline & 20 & \\
\hline & 21 & \\
\hline \multirow{5}{*}{ 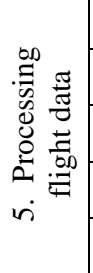 } & 22 & \multirow{5}{*}{$\begin{array}{l}\text { - Uploading the aquired imagery. } \\
\text { - Accessing the flight log. } \\
\text { - Geotagging the pictures in the PostFlight } \\
\text { Suite. } \\
\text { - Orthophotomap generation in Agisoft } \\
\text { Photoscann Professional. } \\
\text { - Generating the geoprocessing report. }\end{array}$} \\
\hline & 23 & \\
\hline & 24 & \\
\hline & 2 & \\
\hline & 26 & \\
\hline \multirow{4}{*}{ 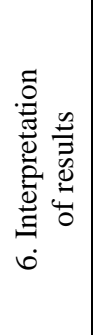 } & 27 & \multirow{4}{*}{$\begin{array}{l}\text { Analysing the outputs of geoprocessing } \\
\text { (orthophoto and DTM) based on the } \\
\text { geoprocessing report. } \\
\text { The principles of photogrammetric image } \\
\text { interpretation. } \\
\text { - Analysing and interpreting the final products } \\
\text { of geoprocessing in the relation to the } \\
\text { research problem stated in the PROJECT } \\
\text { TASK. }\end{array}$} \\
\hline & 28 & \\
\hline & 29 & \\
\hline & 30 & \\
\hline
\end{tabular}

3.1 Block unit 1: Introduction to the subject and the principles of Unmanned Aerial Systems.

In the first block unit, students are introduced to the course. They are provided with the outline of topics covered and the explicit information about assignments and grading procedures. Students should gain a basic understanding of the Unmanned Aerial Vehicle (with examples and classification) functionality of the model used in the course. A brief overview of traditional methods of obtaining spatial data allows the students to notice the need of using UAV, which is crucial for determining the research problem that the students will try to solve using UAV in the project task. During this block unit, students get to know the comprehensive system of UAV swinglet CAM (Fig. 2). The emphasis is placed on functionality and safety procedures.

\subsection{Block unit 2: Flight preparation - theoretical approach}

Basic knowledge must be imparted on technologies, photogrammetric mapping, close range photogrammetry and photogrammetric flight planning principles (Lillesand et al., 2008; Bhatta, 2011; Paine and Kiser, 2012). The formal procedures for obtaining permission for a flight in Poland are presented to the students. They become familiar with the necessary documents as well as legal restrictions for a flight. This information, coupled with the knowledge of topographic requirements, allows the students to determine the preconditions for a potential starting point for the UAV flight.

In the next step they will become familiar with the software dedicated for the flight planning and monitoring swinglet CAM during the flight.

The acquired knowledge will be applied in the PROJECT TASK. Small groups (2-3 students) start the task during the lesson, thus preliminary questions can be answered by a teacher. The project task is the main assignment of the course. Students use acquired theoretical knowledge about flight planning and present their idea for the flight. They need to state the research problem that they will try to solve using data obtained by UAV. The justification for the choice of research area needs to include:

- Stating the research problem - clear identification of a problem and justification of its selection;

- Clear and explicit specification of hypotheses central to the problem selected;

- Description of a research area.

While describing a chosen research area students need to confirm its relevance for the safe flight execution. A brief description of geographical conditions (relief, land use, vegetation types, hydrographic conditions and anthropogenic activity) is required. The main issues that should be taken into consideration include:

- Air traffic safety (possibility of obtaining flight permission)

- Relief and obstacles within the flight area (in case of triggering an emergency procedure, swinglet CAM will fly to the home waypoint at a height of $75 \mathrm{~m}$ ).

Coordinates of take-off location (and the start and home waypoints) need to be determined concerning:

- Accessibility (roads, property status);

- Safe (obstacle-free) $40 \mathrm{~m}$ radius take-off and landing zone

- Altitude of take-off (launching point) location - the zero altitude reference is taken during the startup procedure.

The exact area of the flight, desired output orthophoto resolution, as well as longitudinal and lateral image overlap of the photos and working area radius need to be determined, taking into account the previously stated research problem. 
Apart from this conceptual overview students are also required to provide all of the materials necessary for proper flight planning:

- Topographic map of the neighbourhood:

- digital version in the form of georeferenced imagery;

- paper version, which indicates: exact borders of the area to be covered by the orthophoto, the working area boundary, take-off location and safe (obstacle-free) $40 \mathrm{~m}$ radius takeoff and landing zone;

- Filled documents necessary for obtaining the flight permission in accordance with Polish legal procedures;

- Tiles of a customized base maps of the area;

In order to ensure high precision of flight planning in the dedicated software e-mo-tion, the default base maps (satellite imagery and street view of Google Maps) can be replaced by more detailed custom imagery such as largescale topographical maps. This imagery must be in the form of a hierarchical tile set following the web tiling standard. The free application MapTiler enables the creation of such a tile set from any georeferenced imagery.

\subsection{Block unit 3: Flight preparation - practical approach}

Before starting all of the procedures of creating a flight path, the research idea needs to be chosen. Students introduce their project task to the whole class in the form of a short presentation. After brainstorming all ideas, the best one is chosen for further investigation. It is then discussed and analyzed in order to determine problems and errors and try to solve them through necessary amendments.

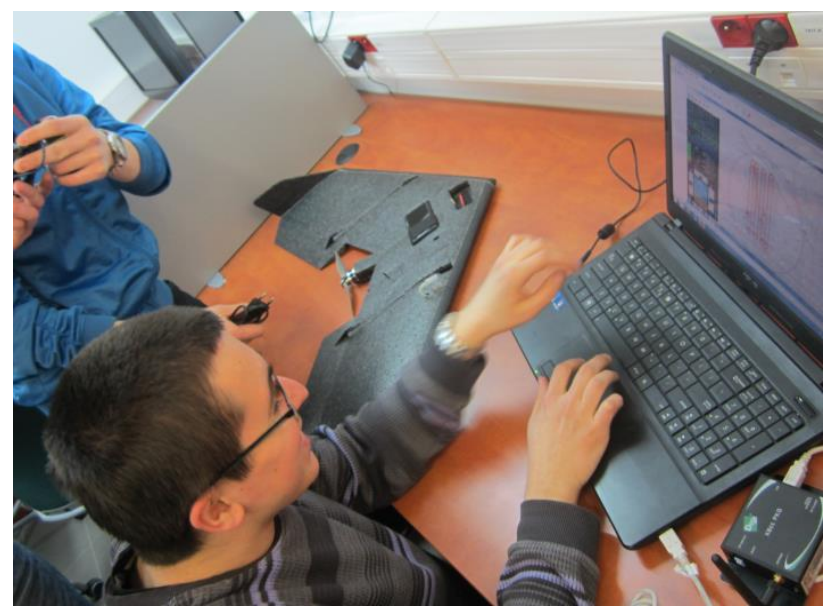

Figure 3. Process of generating automatic flight plan

The practical approach to flight planning includes an automatic flight plan creation in the dedicated software, preparing and submitting the documents necessary for obtaining flight permission and charging all devices needed for flight execution. For photogrammetric flights, this tool will generate a mission plan to systematically cover a designated area by positioning and configuring a set of waypoints. The procedure includes programming the swinglet CAM to take pictures in a systematic way and optimizing parameters - flight altitude and longitudinal and lateral image overlap - to achieve the desired ground resolution. The waypoint route, including photo locations, must be programmed and saved into the memory of the swinglet CAM autopilot.

S Students follow the automatic flight planning procedure using materials and base maps created in the project task by one of the groups. The prepared documents for obtaining flight permission are screened and corrected in case any errors are detected.
The automatic flight planning doesn't take into account the local conditions such as obstacles or uneven terrain. Therefore the resulting flight plan should be carefully reviewed in order to avoid any collision and to comply with local regulations.

Designated students undertake the responsibility for:

- Completing the formalities for the legal UAV flight execution in accordance with Polish Airspace management regulations

- Weather forecasting notification;

- Checking the equipment on the day preceding the planned mission.

Security checks and charging electronic devices are the last stages of flight preparation conducted in the classroom.

\subsection{Block unit 4: Flight (Field Excursion)}

The field excursion significantly enhances the content of the course by providing an opportunity to operate the UAV and use in practice the knowledge acquired in the classroom. Students perform all of the procedures of executing a flight while being supervised by experienced teachers.

Before each flight the weather checks need to be conducted in order to ensure that overly strong wind or rain won't hinder the flight mission (swinglet CAM will fly back home automatically when wind stronger than $7 \mathrm{~m} / \mathrm{s}$ is detected by the autopilot). A risk-based terrain inspection is necessary for confirmation that the environment is sufficiently clear of obstacles for the swinglet CAM to be operated. It is also of utmost importance to cautiously perform preflight checks to ensure flight safety.

Prior to the take-off, the communication between UAV and ground control station is established.

The swinglet CAM is launched by hand and follows a 3D path defined by waypoints, taking pictures at pre-determined moments based on the parameters that were defined during mission planning. During the flight, students monitor and control the status of the swinglet CAM using the ground control station software that displays the position and navigation information. In order to obtain the desired quality of output products, modifying the flight plan during the flight should be limited to a minimum. After accomplishing the automated flight, swinglet CAM lands by gliding down in tight spirals around the home waypoint.

Students gather all the information about the flight mission and summarize them in the flight report sheet.

\subsection{Block unit 5: Processing flight data}

Once the swinglet CAM has landed, the images acquired during the flight are ready to download to the computer. The manufacturer provides PostFlight Suite software that allows the imagery to be geotagged. This process consists of writing the GPS coordinates of the position at which the image has been taken into the image file. The same software can be used as a gateway to purchase the resulting mapping products. From the variety of software that is able to generate a geo-referenced orthomosaic together with a DEM of the surveyed area, Agisoft Photoscan Professional has been chosen for the aim of this course. Although the details of workflow can vary according to the software used, the generic procedure always consists of following steps (Strecha et al., 2012):

- Matching points detection by analyzing all uploaded images;

- Bundle block adjustment - reconstruction of the exact position and orientation of the camera for every acquired image (Tang and Heipke, 1996) using previously detected matching points as well as approximate values of the image position and orientation provided by the UAV autopilot; 
- Verification and calculation of 3D coordinates of reconstructed matching points;

- Interpolation of the matching points to form a triangulated irregular network in order to obtain a DEM;

- Calculation of the georeferenced orthomosaic using generated DEM as a source for projection of every image pixel.

In its basic form, no ground control point (GCP) is used and the geo-localization process only depends on the GPS measurements provided by the UAV. Optionally, GCPs can be added to improve the geolocalisation accuracy (Küng et al., 2011).

Students follow this procedure with the use of the tutorial provided by the software developer.

\subsection{Block unit 6: Interpretation of results}

Prior to beginning the process of photo interpretation, the quality of the data needs to be checked. This can be achieved with the use of the geoprocessing report generated by the software. The image completeness (complete coverage) needs to be assessed and the image stretch (blurring), missing or double image areas identified (Manzer, 1996).

In order to accept or refute hypotheses formulated at the beginning of the study, the final products of geoprocessing need to be analyzed and interpreted. These research hypotheses are considered a subject of photo interpretation conducted in the course. The significance of photo interpretation as a final stage of the workflow: image acquisition - image processing - image interpretation, is explained (Mularz, 2004). Principles of image interpretation understood as the act of examining photographic images for the purpose of identifying objects and judging their significance (Colwell, 1997) are introduced to the students. Strong dependency on the interpreter's knowledge and experience imposing limitations in the automation of the process is emphasized.

The first stage of the conducted photo interpretation process is reviewing existing source material concerning a given area, process, or object. A better definition of the scope, objectives, and problems associated with a given project can be achieved based on collateral material analysis.

The subjective process of photo interpretation from the psychophysiological point of view can be divided into three phases (Ciołkosz et al., 1999):

- Detection of the object;

- Its recognition (identification);

- Evaluation and interpretation of outcomes

The following factors are assessed when trying to identify a feature (Ciołkosz et al., 1999):

- Direct (shape, size, tone/color, texture, structure);

- Indirect (shadow, topographic distribution of the element and its relationship with the environment);

- Comprehensive (combinations of abovementioned factors).

The generic workflow of photo interpretation can be adjusted based on the character of an analyzed phenomenon. The general model was elaborated upon by Ciołkosz et al. (1999) for specific purposes: geological, geomorphological, hydrological studies, vegetation and soil surveys as well as for the economic needs (agriculture, urbanization and urban planning). Students can apply these methods to achieve the objective of photo interpretation in their case study. Students use deductive reasoning in order to verify the hypothesis. The results of this process should allow them to formulate final synthesized conclusions.
At the end, the value of the findings should be assessed, taking into account the degree of recognition, credibility and accuracy of the photo interpretation process (Ciołkosz et al., 1999).

\section{ASSESMENT AND EVALUATION}

The curricular elements that must be completed to pass the course as well as criteria and procedures for arriving at each contributing score need to be clearly stated and presented to the students. Deliverables and assessment of the course consist of:

- Presentation of the PROJECT TASK (20\% of final grade);

- PROJECT TASK turn outs - written and digital materials (40\% of final grade)

- Flight mission report sheet (10\% of final grade);

- Image interpretation and analysis report sheet (20\% of final score).

Students' activity during the class contributes to the remaining $10 \%$ of the final grade.

At the end of the course students are asked to assess the course in the evaluation questionnaire. This useful feedback will be used by a teacher to improve the quality of instruction and adjust the content of the course.

\section{CONCLUSION}

This newly introduced course will give future geographers an opportunity to master the skills of acquiring spatial data using an innovative tool - an Unmanned Aerial Vehicle. Reaching this goal requires that students learn how to use critical thinking and practical application of knowledge to make well-reasoned decisions and to solve research and business problems. This will allow them not only to extend their research skills but also to enhance their competitiveness in the job market.

Developing relevant courses in areas that foster such academic and professional development is an important objective for universities today.

\section{REFERENCES}

Bhatta, B., 2011. Remote Sensing and GIS, 2nd Edition. Oxford University Press, New Delhi, pp. 229-263.

Ciołkosz A., Miszalski J., Olędzki J.R., 1999. Interpretacja zdjęć lotniczych. PWN, Warszawa, pp. 137-432.

Colwell, R. N. (Ed.), 1997. History and Place of Photographic Interpretation, in Manual of Photographic Interpretation, 2nd Ed., W. R. Phillipson (Ed.), Bethesda: ASPRS, 33-48.

Eisenbeiß, H., 2009. UVA photogrammetry. Institut für Geodäsie und Photogrammetrie, Zürich, pp. 1-58.

Küng, O., Strecha, C., Beyeler, A., Zufferey, J. C., Floreano, D., Fua, P., Gervaix, F., 2011. The Accuracy of Automatic Photogrammetric Techniques on Ultra-Light UAV Imagery. Int. Archives of Photogrammetry, Remote Sensing and Spatial Information Sciences, Vol. 38(1/C22), pp. 14-16.

Lillesand, M. T., Kiefer, R. W., Chipman, J. W., 2008. Remote sensing and image interpretation (6th ed.). John Wiley \& Sons, Inc., Hoboken, NJ, pp.123 -188.

Manzer, G., 1996. Avoiding Digital Orthophoto Problems, in Cliff Greve, ed. Digital Photogrammetry-An Addendum to the Manual of Photogrammetry. American Society of Photogrammetry, Bethesda, MD. 
Mularz, S., 2004. Podstawy teledetekcji. Wprowadzenie do GIS. Wydaw. Politechniki Krakowskiej, Krakow, pp. 18-42.

Paine, D, Kiser, J., 2012. Aerial photography and image interpretation. John Wiley \& Sons, Inc., pp. 161-172.

Strecha, C., Fletcher, A., Lechner, A., Erskine, P., Fua P.(2012) Developing species specific vegetation maps using multispectral hyperspatial imagery from unmanned aerial vehicles, ISPRS Annals of Photogrammetry, Remote Sensing and Spatial Information Science, I-3, pp. 311-316.

Tang, L. and Heipke, C., 1996. Automatic relative orientation of aerial images. Photogrammetry and Remote Sensing, 62(1), pp. $47-55$.

\section{ACKNOWLEDGEMENTS}

I would like to thank to my Ph.D. advisor, Professor Tomasz Niedzielski, for his confidence in my ability to teach this course and for giving me the freedom to pursue the task of creating a syllabus for it. Through his scientific expertise, knowledge, and many insightful discussions and suggestions, he has helped me to improve my own teaching skills and further my academic development. 